\title{
Barium-induced skeletal muscle paralysis in the rat, and its relationship to human familial periodic paralysis
}

\author{
G. D. SCHOTT AND B. MCARDLE \\ From the Department of Chemical Pathology, Guy's Hospital, London
}

SUMMARY An in vivo study of skeletal muscle paralysis induced by intravenous barium chloride has been made in curarized and non-curarized rats. The influence of potassium and calcium chlorides, propranolol, ouabain, and prior adrenalectomy on the paralysis has also been studied. Paralysis is found to be due to a direct effect on skeletal muscle, and to correlate well with the development of hypokalaemia. Possible mechanisms of action of barium are discussed, and attention is drawn to the similarity between barium poisoning and hypokalaemic familial periodic paralysis.

The similarity between periodic paralysis and barium poisoning was first appreciated in China. An endemic illness, Pa Ping, characterized by sometimes fatal episodes of paralysis, was for many years prevalent in the Szechwan province of western China.

A series of papers on Pa Ping, introduced by that of Allen (1943), reported in considerable detail the investigation of the disease, and its cause was traced to the very high barium content in the local salt. Huang (1943) wrote that the cases 'showed symptoms almost completely identical with the description of the rare disease called "family periodic paralysis" ...', and suggested that a disturbance in 'the potassium ion equilibrium in the body' might be responsible. Only very occasional reference to this striking observation has since been made (Diengott et al., 1964; Zierler, 1970), and despite its similarity to periodic paralysis, few investigations have been described of the way in which the soluble salts of this element exert their profound and characteristic effect. Hypokalaemia associated with barium poisoning was demonstrated, together with the electrocardiographic (ECG) changes typical of low plasma potassium, by Diengott et al. (1964).

Paralysis of skeletal muscle, flaccid in type, is a frequent though not invariable feature of barium

1 Member of the External Scientific Staff, Medical Research Council. poisoning. The weakness, which occasionally is preceded by a diffuse aching in the muscles affects earliest and most severely the limbs, but may proceed to involvement of the trunk, and later the respiratory, neck, and bulbar musculae ture. It is global in distribution, and unrelated to nerve distribution. There are no apparent charac? teristic features indicative of its aetiology.

The present experiments have been undertaken to investigate some aspects of this paralysis, and in particular to ascertain the site of the paralysing action of barium. Although barium has several other effects on man and animals (Welt and Blythe, 1970), these effects-which include hypertension, smooth muscle stimulation, and production of cardiac arrhythmias-have not been specifically investigated during the course of this study.

\section{METHODS}

Experiments were performed on Wistar strain $\mathrm{GH} 2$ rats of either sex, weighing 150-250 g, anaesthetized with intraperitoneal urethane $(15 \mathrm{ml} . / \mathrm{kg}$ of a $10 \%$ solution). Respiration where necessary was maintained with a ventilator pump (Palmer). Contractions of the gastrocnemius/plantaris/soleus muscle group were elicited indirectly by stimulation of the distal end of the cut sciatic nerve, using rectangular current pulses of $0.5 \mathrm{msec}$ duration delivered at a rate of $6 / \mathrm{min}$, and about twice the strength necessary 
to produce a maximal twitch. Directly-elicited contractions of the fully curarized tibialis anterior muscle were obtained by similar means, using a silver wire attached to the musculotendinous junction and a steel needle electrode driven into the femur.

Pilot experiments indicated that complete and maintained neuromuscular blockade was produced by intravenous injections of tubocurarine, $0.6 \mathrm{mg} / \mathrm{kg}$, repeated at 20 to 30 minute intervals, and curarization thus effected avoided the necessity for two simultaneous infusions (see below).

Muscles were bathed continuously in mineral oil (heavy liquid paraffin B.P.) maintained at a temperature of $37 \pm 1^{\circ} \mathrm{C}$, recorded in the fluid a few millimetres away from the muscle. The rectal temperature was also kept at $37^{\circ} \mathrm{C}$ by means of a heating lamp placed above the animal. The leg was firmly clamped as horizontally as possible to reduce heat loss (Bigland and Zaimis, 1958), the resting length of the muscle adjusted to give a maximum twitch tension, and contractions recorded on a 4-channel recorder (Devices), by means of an isometric tension transducer (E.E.L., Model 2STO2) attached to the appropriate tendon.

Drugs were injected intravenously through a cannula in the jugular vein, or intra-arterially through a cannula introduced into the femoral artery of the leg contralateral to that subsequently to be dissected. Arterial blood samples were also obtained from this cannula. Carotid blood pressure was recorded continuously using a pressure transducer (Consolidated Electrodynamics, Model 4-327-L221), and heart-rate by means of an instantaneous ratemeter (Devices). Adrenalectomy where indicated was performed through bilateral paravertebral incisions, immediately after induction of anaesthesia. Despite the similar results obtained with barium chloride made up in isotonic saline, and the negligible quantity of chloride introduced, barium chloride was made up in isotonic sodium acetate, since certain electrophysiological experiments (Sperelakis et al., 1967) had indicated that chloride could have a masking action on some barium-induced effects. The barium chloride solution was administered by slow intravenous infusion, using a motorized syringe (Palmer); and in experiments in which plasma barium concentration was determined, ${ }^{131} \mathrm{BaCl}_{2}$ (Radiochemical Centre, Amersham) was added, to provide approximately $20 \mu \mathrm{c} / \mathrm{ml}$. barium chloride solution injected. The radioactive barium contributed less than $0.1 \%$ total barium injected; and the arterial plasma barium concentration was determined by measurement of radioactivity, using a well scintillation counter (Dynatron). Arterial plasma sodium and potassium concentrations were determined by flame photometry (Instrumentation Laboratories, Model
143), preliminary experiments demonstrating the absence of effect of barium on this technique. Plasma for these determinations was obtained by one minute centrifugation in a Beckman Spinco-152 microfuge of $0.2 \mathrm{ml}$. blood samples, the latter being replaced with the same volume of $0.9 \% \mathrm{w} / \mathrm{v}$ saline.

The drugs used were: d-tubocurarine chloride (Burroughs Wellcome); barium chloride, $2 \mathrm{H}_{2} \mathrm{O}$; calcium chloride, $2 \mathrm{H}_{2} \mathrm{O}$; potassium chloride (British Drug Houses); isoprenaline sulphate B.P. (Macarthy); propranolol hydrochloride (Imperial Chemical Industries), ouabain (Nativelle Laboratories). Aqueous stock solutions were used, diluted with $0.9 \% \mathrm{w} / \mathrm{v}$ saline where appropriate, except in the case of barium chloride solution. The drugs were administered in a volume of $0.1-0.5 \mathrm{ml}$, and flushed in with $0.2 \mathrm{ml} .0 .9 \% \mathrm{w} / \mathrm{v}$ saline. Solutions are expressed in terms of the salts.

\section{RESULTS}

EFFECTS OF BARIUM CHLORIDE ON MUSCLE CONTRACTION The effects of barium chloride on muscle contraction elicited by supramaximal indirect and direct muscle stimulation are illustrated respectively in Figs 1 and 2. Both show the same features, found to be consistent in those animals in which unequivocal paralysis was obtained by use of an effective dose of barium chloride (see below), and in which the animal's general condition remained unimpaired, as indicated by maintenance of a satisfactory blood pressure, and where appropriate, respiration. These effects consist of: (1) a period of increased muscle contraction, commencing within a few minutes of the barium infusion and lasting 10-15 minutes; in 11 animals studied, the increase

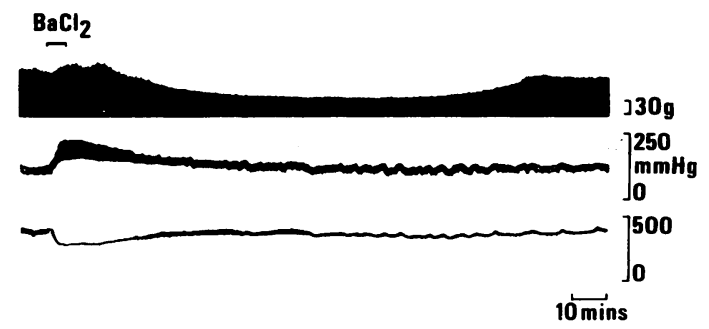

FIG. 1. The effect of an intravensus infusion of barium chloride $(24.5 \mathrm{mg} / \mathrm{kg})$ on indirectly-elicited twitches of the gastronnemius group of muscles (upper record), arterial blood-pressure (middle record), and heart-rate (lower record). 


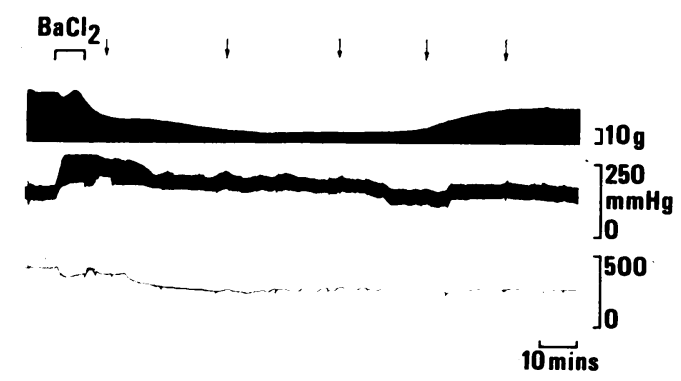

FIG. 2. The effect of an intravenous infusion of barium chloride (16 $\mathrm{mg} / \mathrm{kg}$ ) on directly-elicited twitches of the tibialis anterior muscle (upper record), arterial blood-pressure (middle record), and heart-rate (lower record). Curarization maintained by intravenous injections of tubocurarine $(0.6 \mathrm{mg} / \mathrm{kg})$, indicated by arrows.

ranged from $5-60 \%$ (mean $38 \%$ ) above the basal contraction amplitude; (2) a partial paralysis, followed by (3) spontaneous recovery. The partial paralysis was manifested by a prolonged period of reduced contractions, lasting $30 \mathrm{~min}$ utes to more than two hours, in the rats that recovered. Of the 11 animals referred to above, seven made a complete or partial recovery, and in these, the reduced contractions were $30-80 \%$ of the control value (mean 50\%); the others either died or failed to demonstrate any recovery, and hence a reasonable state of the preparation could not be assured.

The effective paralysing dose of barium chloride was found empirically to be $16-25 \mathrm{mg} /$ $\mathrm{kg}$, administered at a rate of $0.5 \mathrm{mg} / \mathrm{min}$. Higher doses were more often fatal, although fatalities still occurred in the dose range indicated above. Lower doses usually did not result in paralysis. although they would frequently give the first phase of increased contraction. Death was likely to occur if the barium was given as a rapid bolus; and prolonged, slow infusion often failed to cause any reduction in muscle contraction. It was not possible to correlate the degree of paralysis with the dose of barium administered using this preparation; and it was evident that the effective dose was close to the lethal dose.

The degree and duration of the phases wero variable. Generally the degree of potentiation of muscle contraction during phase (1) was no found to correlate with the subsequent decrease of phase (2); and exceptionally, the two phases

FIG. 3. The effect of an intravenous infusion of barium chloride $(22 \mathrm{mg} / \mathrm{kg})$ on indirectly-elicited maximal $\underset{2}{0}$ twitches of the gastrocnemius group of muscles, and plasma barium and potassium concentrations. 
were separated entirely by a period of contractions of basal amplitude.

CORRELATION OF PLASMA ION CONCENTRATION WITH MUSCLE CONTRACTION The plasma sodium, potassium and barium ion concentrations were determined concurrently with the amplitude of muscle contraction, and an example is shown in Fig. 3; the plasma sodium concentration remained unchanged at $131-136 \mathrm{mEq} / \mathrm{l}$. There is a decrease in plasma potassium concentration, which is striking in its degree and rapidity of onset. The plasma barium concentration during the course of the experiment was 5-100 $\mu \mathrm{g} \mathrm{BaCl}_{2} /$ $\mathrm{ml}$., and, unlike the plasma potassium concentration, did not show a subsequent rise after the initial fall. The plasma ion concentrations were not studied during the brief, initial phase of enhanced muscle contraction; but there is an evident and marked correlation between contraction amplitude and plasma potassium level, a correlation not observed with the plasma barium or sodium levels.

In eight animals, the control plasma potassium concentration values ranged from 3.9-4.6 (mean $4.2) \mathrm{mEq} / \mathrm{l}$. The lowest values of plasma potassium concentration attained in five treated rats which recovered from barium-induced paralysis ranged from $1 \cdot 8-2 \cdot 3$ (mean $2 \cdot 0$ ) $\mathrm{mEq} / \mathrm{l}$; ; and thus barium reduced the initial plasma potassium concentration by about one half.

It should be noted that the blood samples were unavoidably replaced with saline to maintain the fluid volume; it is possible therefore that this added saline could give rise to some misleading observations of the plasma ion concentrations.

EFFECT OF ADRENALECTOMY The possibility that paralysis might be due to an effect mediated through barium-induced adrenal catecholamine release (Douglas and Rubin, 1964) was investigated, since adrenaline administration is known to be associated with an initial hyperkalaemia that is followed by prolonged hypokalaemia (D'Silva, 1934). Furthermore, administration of adrenaline may precipitate attacks of weakness in patients with familial periodic paralysis (Allott and McArdle, 1938). Bilateral adrenalectomy in four rats did not affect the development of paralysis, or the cardiovascular events (see below).

EFFECT OF PROPRANOLOL The hypokalaemia following the injection of adrenaline noted by D'Silva was subsequently found to be a function of adrenergic beta-receptor stimulation (Powell and Skinner, 1966; Todd and Vick, 1971; Vick et al., 1972). The ability of a beta-receptor blocking drug to reverse the paralysis induced by barium was therefore investigated. Propranolol was given intravenously in a dose of $0.5 \mathrm{mg} / \mathrm{kg}$, a dose sufficient to abolish a fall in blood-pressure induced with $0.5-5 \mu \mathrm{g} / \mathrm{kg}$ isoprenaline. Propranolol in this dose, and also in a considerably higher dose of $4-5 \mathrm{mg} / \mathrm{kg}$, failed to reverse the barium-induced paralysis in six animals. The muscle response was also unaltered when propranolol was given prophylactically $0-30$ minutes before the barium.

EFFECT OF POTASSIUM CHLORIDE Injection of potassium chloride intra-arterially close to the femoral artery of the dissected leg, in a dose of $37-75 \mathrm{mg} / \mathrm{kg}$, resulted in a temporary increase in muscle contraction elicited indirectly or directly, both before and during barium-induced paralysis in four rats. Though these findings confirm the beneficial effect of potassium salts, and indeed potassium could be expected considerably to enhance contraction in conditions of hypokalaemia, they provide little information as to the mode of action of barium.

EFFECT OF CALCIUM CHLORIDE The effect of calcium was investigated, with a particular view to determining whether 'competition' could be demonstrated between these two divalent alkaline-earth cations. Calcium chloride, $15 \mathrm{mg} / \mathrm{kg}$, given in a similar way to potassium chloride, and in approximately equimolar amounts to the barium administered, on one occasion reduced the contractions of indirectly-stimulated muscle a further $10 \%$ of that produced by barium. However, in three other instances, it did not alter the contraction response, even when given in repeated doses totalling $75 \mathrm{mg} / \mathrm{kg}$ over a period of about one hour.

EFFECT OF OUABAIN The effect of ouabain was investigated in view of its well-known effects on 
membrane function, in particular its inhibiting effect on $\mathrm{Na}^{+}-\mathrm{K}^{+}$-stimulated ATPase and the sodium pump. Within two minutes of its injection, intravenous ouabain in a dose of $0.5-1.5$ $\mathrm{mg} / \mathrm{kg}$ was found unequivocally to reverse barium-induced paralysis of muscles stimulated directly or indirectly in four animals. The effect is illustrated in Fig. 4. Given before barium

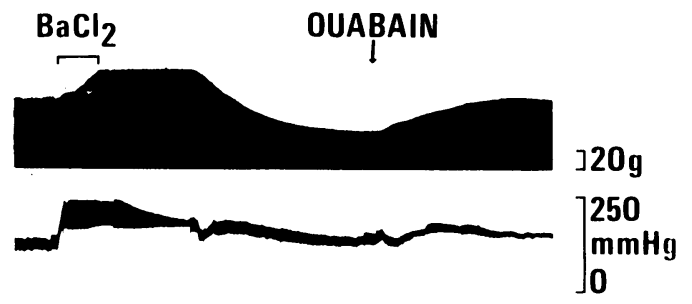

10 mins

FIG. 4. The effect of intravenous ouabain $(0.5 \mathrm{mg} /$ $\mathrm{kg}$ ) on the indirectly-elicited maximal twitches of the gastrocnemius group of muscles (upper record) and blood pressure (lower record) of a rat, treated with an intravenous infusion of barium chloride $(21 \mathrm{mg} / \mathrm{kg})$. Due to limitation of the recording system, only part of the potentiation of muscle contraction is seen.

administration, it did not prevent paralysis; moreover, in control, curarized animals, it produced an increase in contraction lasting about 15 minutes. When given in small doses $(5-10 \mu \mathrm{g} / \mathrm{kg})$, ouabain had no effect on the paralysis.

CARDIOVASCULAR AND GENERAL EFFECTS OF BARIUM The hypertensive action noted by many previous workers (Cathcart and Clark, 1915; Roza and Berman, 1971) was confirmed: the blood pressure rose when even minute amounts of barium had entered the circulation. The blood pressure sometimes doubled within three minutes, and the heart-rate fell as the pulse pressure widened. These effects are illustrated in Figs 1 and 2, where they can be seen in relation to the changes in muscle contraction. It is evident that there is no apparent correlation between the cardiovascular and the muscular events: in particular, hypertension was invariably produced regardless of the presence and degree of paralysis (or increased contraction). Hypertension was not apparently affected by any of the substances administered, nor by adrenalectomy.

Although electrocardiograms were not re- corded, the presence of arrhythmias could be inferred from observation of the apex beat, the irregular movement of the column of blood in the carotid cannula, and irregularities produced in the heart-rate record. By these criteria, arrhythmias were not infrequently noted 30 minutes to one hour after barium administration, when death was most likely to occur. There was no apparent correlation between these arrhythmias and the development of paralysis.

A mucoid diarrhoea and profuse urination, both well-known effects of barium, were often observed 30 minutes to one hour after barium infusion.

The lethal effects of barium were considered to be due to cardiac or respiratory failure, or both. Cardiac failure was often associated with the development of arrhythmias, but the contribution of other factors, such as the very considerable hypertension, could not be assessed. Respiratory failure was probably implicated in those non-curarized and non-ventilated animals, in which extreme paralysis affecting the respiratory muscles presumably resulted in ventilatory fail ure.

\section{DISCUSSION}

The administration of barium has for long been known to cause skeletal muscle paralysis, an effect observed both in animal experiments (Orfila, 1816; Cyon, 1866) and in cases of human poisoning with barium salts (Huang, 1943; Morton, 1945; Lewi and Bar-Khayim, 1964). The present studies indicate that this paralysis is due, although not necessarily primarily or exclusively, to a direct effect produced by barium on skeletal muscle.

The effect of barium is exceptional, for acute, transient paralysis with hypokalaemia is not a feature of administration of the other alkalineearths, calcium or strontium. In this study, the lack of effect of calcium administration on the paralysis produced by barium supports the view that simple divalent cation 'competition' is unlikely to be a significant factor.

Since the time course of development of paralysis correlates well with that of hypokalaemia, but not with changes in the plasma barium concentration, a fundamental role of the potassium ion may be inferred. It is of consider- 
TABLE

COMPARISON BETWEEN SOME FEATURES OF BARIUM POISONING AND HYPOKALAEMIC PERIODIC PARALYSIS

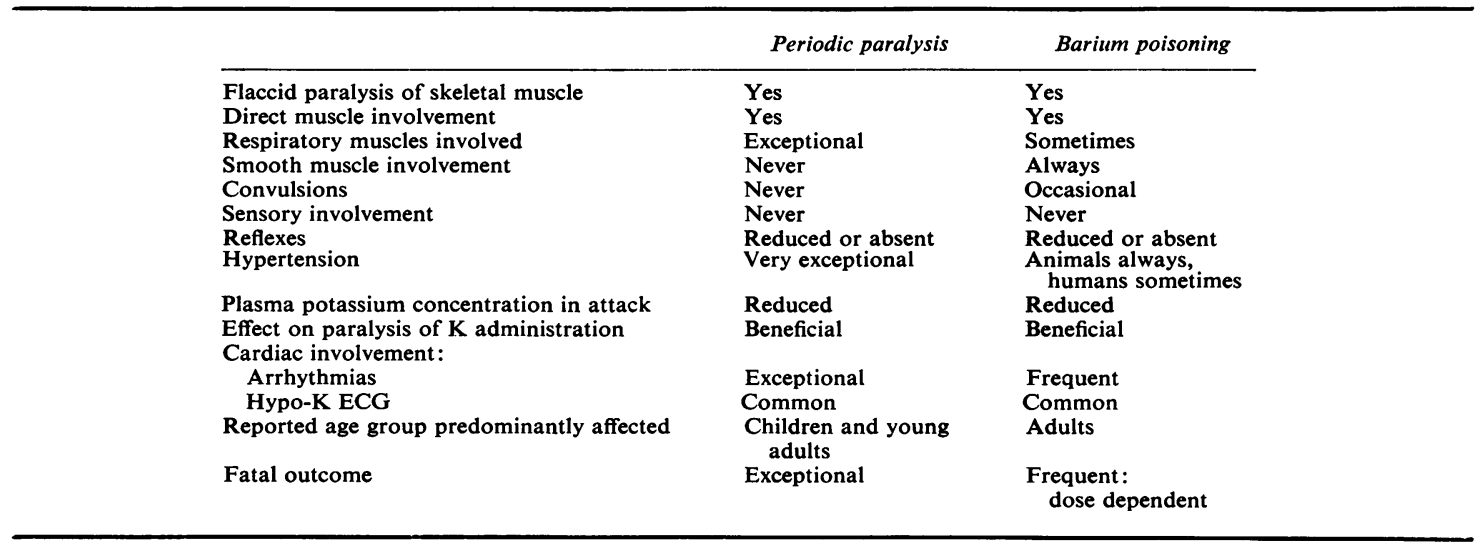

able interest that the paralysis induced by barium bears striking similarities to the hypokalaemic type of human periodic paralysis. The features of the periodic paralyses are well known, and have recently been reviewed (McArdle, 1969; Pearson and Kalyanaraman, 1972). It is relevant that in the hypokalaemic variety the plasma potassium concentration falls, often to low levels, in association with episodes of paralysis; the concentration tends to return towards normal during recovery, and of course responds to potassium salts administered in adequate dosage. Some of the features of barium-induced paralysis and hypokalaemic periodic paralysis are compared in the Table.

Of the many causes of skeletal muscle paralysis, the association with transient hypokalaemia, common to both barium and hypokalaemic periodic paralyses, is unusual; and some of the ways in which such a hypokalaemia in barium poisoning could arise and its possible significance to paralysis will therefore be considered.

That urinary loss cannot account for the lowered plasma potassium concentration has been demonstrated by Roza and Berman (1971), and furthermore the rapid lowering and subsequent restoration of the plasma potassium concentration makes urinary (or faecal) potassium loss most unlikely as a relevant factor. An effect due to dilution is also considered improbable, since the plasma sodium concentration remains essentially unchanged. It would appear reason- able to speculate that the hypokalaemia could be accounted for by increased potassium uptake into the muscle cell, especially since potassium uptake into the erythrocytes of barium-treated dogs has been shown to occur (Roza and Berman, 1971).

A more detailed consideration of the ways in which such an increase in intracellular potassium concentration with hypokalaemia could occur may be outlined. (1) Barium-induced stimulation of adrenergic beta-receptors could cause hypokalaemia, since, as has been discussed above, stimulation of these receptors is known to cause increased intracellular potassium uptake. Such an effect is considered unlikely, since propranolol did not affect the paralysis induced by barium. Moreover, the lack of effect of adrenalectomy in these present experiments further suggests that catecholamines, at least of adrenal origin, play little or no part in the production of paralysis, although barium greatly increases adrenal catecholamine secretion (Douglas and Rubin, 1964). (2) Insulin and glucose administration is well known to be associated with intracellular potassium uptake, and barium, at least in certain in vitro experiments, can replace the necessary role of calcium in glucose-stimulated insulin release (Hales and Milner, 1968); this is unlikely to be a causative mechanism in the production of paralysis, since even large doses of insulin are associated with paralysis only in exceptional conditions, such as occasionally arise 
during the treatment of diabetic coma. The peculiar susceptibility of patients with hypokalaemic periodic paralysis to the development of paralysis on administration of insulin and glucose is of interest in this context. (3) Potassium efflux from cells could be relatively reduced by barium, causing in time an effective retention of intracellular potassium. It may be relevant that patients with hypokalaemic periodic paralysis can often prevent an attack of paralysis by undertaking moderate exercise, possibly by inducing the loss of potassium that normally occurs on exercise (Grob et al., 1957). Barium might act by preventing potassium efflux, since it is well known from electrophysiological experiments to reduce potassium fluxes across, among others, muscle cell membranes (Volle, 1970; Henderson and Volle, 1972). The effect on potassium fluxes may perhaps be due to the similarity in size between the crystal radii of the potassium and barium ions, although any reduction in potassium fluxes would have to affect the efflux more than the influx. (4) The hypokalaemia could be secondary to changes in intracellular metabolism. For instance, potassium uptake could be related to changes in carbohydrate metabolism, or to any increase in intracellular negativity. (5) Disturbance in cell membrane function is a further possibility that may be considered. In circumstances where the membrane $\mathrm{Na}^{+}-\mathrm{K}^{+}$-stimulated ATPase activity is enhanced, excess intracellular potassium could accumulate, as has been demonstrated in work on high and low potassium-containing erythrocytes of certain animal species (Christinaz and Schatzmann, 1972). Whether barium enhances this membrane ATPase activity is at present controversial: although enhancement was initially demonstrated on cultured myocardial cell $\mathrm{Na}^{+}-\mathrm{K}^{+}$-stimulated ATPase (Henn and Sperelakis, 1968), the enzyme system was subsequently found to be more complex than had previously been thought (Sperelakis and Lee, 1971). The potentiating effect of ouabain in suitable dosages on muscle contraction is well known (Faust and Saunders, 1957). Although the effect of ouabain in the present experiments could be accounted for by inhibition of the $\mathrm{Na}^{+}-\mathrm{K}^{+}$-stimulated ATPase, and resultant loss of intracellular potassium, in view of the very many and nonselective effects that ouabain can produce under in vivo conditions, such a hypothesis must at present remain entirely speculative.

The relationship of the hypokalaemia to the paralysis induced by barium is poorly understood, as indeed it is in hypokalaemic periodic paralysis. Furthermore, it should be pointed out that the changes in plasma potassium concentration could be entirely secondary to other effects of barium and unrelated aetiologically to the paralysis. Data concerning changes in the resting membrane potential in in vivo barium poisoning are at present unavailable, but the unexpected findings in hypokalaemic periodic paralysis that the in vivo resting potential is unchanged (Shy et al., 1961) or reduced (Riecker and Bolte, 1966), despite theoretical predictions that hyperpolarization should occur, may be recalled.

Numerous other factors that are likely to be highly important may have to be taken into account. Many such factors have been considered, and in some instances explored, in the case of hypokalaemic periodic paralysis, and include: the form (free, bound, or compartmentalized) in which intracellular potassium might exist; whether the concentration or only the content of potassium is increased (Shy et al., 1961) the role of sodium and calcium ions; the relation ship of the membrane potential to the contractile response (Merton, 1956); whether more than one type of potassium channel is involved; changes in muscle cell diameter and hence in membrane properties; the function of the sarcoplasmic reticulum; and changes in intracellular metabolism.

Although certain of these factors have been investigated in periodic paralysis, the aetiology of this disease has remained elusive. The present finding of the direct paralysing effect of barium on muscle, associated with hypokalaemia, lends support to the observation of Huang (1943) of the similarity between barium poisoning and periodic paralysis. It is possible that the unique properties of barium could provide an experimental model for the study of certain aspects of familial periodic paralysis.

The authors are most grateful to Professor W. D. M. Paton, F.R.S. for valuable guidance, Dr. Anne Warner for helpful discussion, and Dr. B. V. Robinson and Mr. P. J. Morrison for technical advice. This work forms part of a MD dissertation 
submitted to the University of Cambridge by G.D.S., who is also indebted to the Charles E. Merrill Trust for financial support.

\section{REFERENCES}

Allen, A. S. (1943). Pa Ping, or Kiating paralysis. Chinese Medical Journal, 61, 296-301.

Allott, E. N., and McArdle, B. (1938). Further observations on familial periodic paralysis. Clinical Science, 3, 229-239.

Bigland, B., and Zaimis, E. (1958). Factors influencing limb temperature during experiments on skeletal muscle. Journal of Physiology, 141, 420-424.

Cathcart, E. P., and Clark, G. H. (1915). The action of barium chloride on the vascular system. Journal of Physiology, 50, 119-127.

Christinaz, P., and Schatzmann, H. J. (1972). High potassium and low potassium erythrocytes in cattle. Journal of Physiology, 224, 391-406.

Cyon, M. (1866). Ueber die toxischen Wirkungen der Barytund Oxalsäureverbindungen. Archiv für Anatomie, Physiologie und wissenschaftliche Medizin, 196-203.

Diengott, D., Rozsa, O., Levy, N., and Muammar, S. (1964). Hypokalaemia in barium poisoning. Lancet, 2, 343-344.

Douglas, W. W., and Rubin, R. P. (1964). Stimulant action of barium on the adrenal medulla. Nature, 203, 305-307.

D'Silva, J. L. (1934). The action of adrenaline on serum potassium. Journal of Physiology, 82, 393-398.

Faust, R. M., and Saunders, P. R. (1957). Comparative effects of ouabain upon contractile force of guinea pig diaphragm and heart. Proceedings of the Society for Experimental Biology and Medicine, 94, 351-356.

Grob, D., Liljestrand, A., and Johns, R. J. (1957). Potassium movement in normal subjects. American Journal of Medicine, 23, 340-355.

Hales, C. N., and Milner, R. D. G. (1968). Cations and the secretion of insulin from rabbit pancreas in vitro. Journal of Physiology, 199, 177-187.

Henderson, E. G., and Volle, R. L. (1972). ${ }^{42} \mathrm{~K}$-exchange in frog muscle treated with 9-aminoacridine (9AA) or barium. (Abstract.) Federation Proceedings, 31, 557.

Henn, F. A., and Sperelakis, N. (1968). Stimulative and protective action of $\mathrm{Sr}^{2+}$ and $\mathrm{Ba}^{2+}$ on $\left(\mathrm{Na}^{+}-\mathrm{K}^{+}\right)$-ATPase from cultured heart cells. Biochimica et Biophysica Acta, 163, 415-417.

Huang, K-W. (1943). Pa Ping (transient paralysis simulating family periodic paralysis). Chinese Medical Journal, 61, 305-312.

Lewi, Z., and Bar-Khayim, Y. (1964). Food-poisoning from barium carbonate. Lancet, 2, 342-343.

McArdle, B. (1969). Metabolic and endocrine myopathies. In Disorders of Voluntary Muscle, pp. 607-638. Edited by J. N. Walton, 2nd edn. Churchill: London.
Merton, P. A. (1956). Problems of muscular fatigue. British Medical Bulletin, 12, 219-221.

Morton, W. (1945). Poisoning by barium carbonate. Lancet, 2, 738-739.

Orfila, M. P. (1816). A General System of Toxicology. Translated from the French. Vol. 1, pp. 389-401. Cox: London.

Pearson, C. M., and Kalyanaraman, K. (1972). The periodic paralyses. In The Metabolic Basis of Inherited Disease, edited by J. B. Stanbury, J. B. Wyngaarden, and D. S. Fredrickson, 3rd edn., pp. 1181-1203. McGraw-Hill: New York.

Powell, W. J., Jr., and Skinner, N. S., Jr. (1966). Effect of the catecholamines on ionic balance and vascular resistance in skeletal muscle. American Journal of Cardiology, 18, 73-82.

Riecker, G., and Bolte, H. D. (1966). Membranpotentiale einzelner Skeletmuskelzellen bei hypokaliämischer periodischer Muskelparalyse. Klinische Wochenschrift, 44, 804807.

Roza, O., and Berman, L. B. (1971). The pathophysiology of barium: hypokalemic and cardiovascular effects. Journal of Pharmacology and Experimental Therapeutics, 177, 433-439.

Shy, G. M., Wanko, T., Rowley, P. T., and Engel, A. G. (1961). Studies in familial periodic paralysis. Experimental Neurology, 3, 53-121.

Sperelakis, N., and Lee, E. C. (1971). Characterization of $\left(\mathrm{Na}^{+}, \mathrm{K}^{+}\right)$-ATPase isolated from embryonic chick hearts and cultured chick heart cells. Biochimica et Biophysica Acta, 233, 562-579.

Sperelakis, N., Schneider, M. F., and Harris, E. J. (1967). Decreased $\mathrm{K}^{+}$conductance produced by $\mathrm{Ba}^{+}+$in frog sartorius fibers. Journal of General Physiology, 50, 15651583.

Todd, E. P., and Vick, R. L. (1971). Kalemotropic effect of epinephrine: analysis with adrenergic agonists and antagonists. American Journal of Physiology, 220, 1964 1969.

Vick, R. L., Todd, E. P., and Luedke, D. W. (1972). Epinephrine-induced hypokalaemia: relation to liver and skeletal muscle. Journal of Pharmacology and Experimental Therapeutics, 181, 139-146.

Volle, R. L. (1970). Blockade by barium of potassium fluxes in frog sartorius muscle. Life Sciences, Part 1, 9, 175-180.

Welt, L. G., and Blythe, W. B. (1970). Cations: calcium, magnesium, barium, lithium, and ammonium. In The Pharmacological Basis of Therapeutics, p. 814. 4th edn. Edited by L. S. Goodman and A. Gilman. Macmillan: London.

Zierler, K. L. (1970). Diseases of muscle. In Biochemical Disorders in Human Disease, pp. 489-521. 3rd edn. Edited by R. H. S. Thompson and I. D. P. Wootton. Churchill: London. 